\title{
Sustainable production of hydrogen via steam reforming of furfural (SRF) with Co-catalyst supported on sepiolite
}

\author{
S. Sayas, J.F. Da Costa-Serra, A. Chica* \\ Instituto de Tecnología Química (Universitat Politècnica de València-Consejo Superior de \\ Investigaciones Científicas), Avd. de los Naranjos s/n, 46022 Valencia (Spain). \\ *Corresponding author. Tel.: +34 9638770 00-78508; fax: +34 963877809 . \\ E-mail address: achica@itq.upv.es
}

\begin{abstract}
Natural sepiolite is a mineral very abundant in Spain, being the main producer worldwide. This material is presented by the first time as promised support to prepare cobalt catalysts with high activity and hydrogen selectivity in the steam reforming of furfural (SRF). Two methods for cobalt incorporation on natural sepiolite, precipitation (PP) and incipient wetness impregnation (IWI), are explored and their influence in the preparation of catalysts highly active and selective in the SRF is studied. PP method makes possible to synthesize a catalytic material with high catalytic performance (high conversion of furfural, $>95 \%$, and high hydrogen selectivity, $70 \%$ ). Furthermore the production of non-desired byproducts such as $\mathrm{CO}, \mathrm{CH}_{4}$ and acetone, decrease significantly in the catalyst prepared by PP (CoSep). Characterization by $\mathrm{N}_{2}$ adsorption-desorption to determine surface area, XRD, TPR and TEM shows that PP method favors the formation of smaller metallic particles of Co with a high dispersion. These differential physicochemical properties seem to explain the better catalytic performance exhibited by the sepiolitic catalyst prepared by the PP method (CoSep). In addition, this catalyst exhibits also a higher resistance to deactivation after 24 hours of reaction time. This fact seems to be related to the lower coke deposition on the catalyst prepared by precipitation and particularly, with the lower sinterization of the metallic Co particles during the steam reforming of furfural.
\end{abstract}

Keywords: Steam reforming, Cobalt Catalyst, Natural Sepiolite, Hydrogen Production, Furfural. 


\section{Introduction.}

Humanity is between despair and hope for the climatic challenges it faces. The youth leads a current that demands drastic changes in society at all levels to minimize $\mathrm{CO}_{2}$ emissions and try to mitigate the possible effects of climate change. Considering this panorama, hydrogen could be one of the most important alternative fuel on a near future. The use of oil, natural gas, and coal is characterized in recent years for the crescent scarcity of these not renewable energy sources, the increment of their price and, particularly, for the high levels of $\mathrm{CO}_{2}$ emissions generated during their combustion. In this last aspect is where the use of hydrogen as fuel takes an special importance, since its combustion does not produce pollutants, only produce water as byproduct [1]. Currently, hydrogen is produced industrially from natural gas reforming, a non-renewable feedstock. Thus, renewable and environmentally friendly sources for the sustainable production of hydrogen would be need [2,3]. The use of biomass-derived compounds could be an interesting option. Among them, furfural can be considered a promising hydrogen source since it is widely produced worldwide (300,000 tons/year) [4] from different agricultural byproducts such as corncobs, oat, wheat bran, sawdust, rice husk $[5,6]$. Furfural can be also obtained as byproduct in the fast pyrolysis of biomass [7]. The bio-oil obtained in fast pyrolysis can be separated into two phases, an oil fraction suitable to produce hydrocarbons or products with high added value and a non-useful aqueous phase containing a complex mixture of organic compounds where furfural can be considered one of the most representative compounds. Currently, several studies focused on the development of catalysts for the steam reforming of the oil phase to produce hydrogen can be found [8-10]. However, the catalytic reforming of the aqueous phase has not been properly considered yet. An approximation to the study of the steam reforming of the aqueous phase would be the separated study of some of its components in the steam reforming reaction. Thus, the study of the steam reforming of furfural (SRF) as model compound to develop efficient catalysts for the steam reforming of the aqueous phase would be an interesting option.

The main reaction in the steam reforming of furfural is presented in equation (1). In addition, other side reactions, as presented in the equations (2) and (3), can also take place.

$\mathrm{C}_{5} \mathrm{H}_{4} \mathrm{O}_{2}+3 \mathrm{H}_{2} \mathrm{O} \leftrightarrow 5 \mathrm{CO}+5 \mathrm{H}_{2} \Delta \mathrm{H}^{0}=322 \mathrm{~kJ} / \mathrm{mol}$

Water gas shift

$\mathrm{CO}+\mathrm{H}_{2} \mathrm{O} \leftrightarrow \mathrm{CO}_{2}+\mathrm{H}_{2} \Delta \mathrm{H}^{0}=-41 \mathrm{~kJ} / \mathrm{mol}$

Methanation

$$
\mathrm{CO}+3 \mathrm{H}_{2} \leftrightarrow \mathrm{CH}_{4}+\mathrm{H}_{2} \mathrm{O} \Delta \mathrm{H}^{0}=-206 \mathrm{~kJ} / \mathrm{mol}
$$


As it can be seen, hydrogen can be product and reagent. In addition, the thermal decomposition or cracking of different byproducts can compete with the SRF reaction and carbon deposition can occur by different routes such as Boudouard reaction, ethene polymerization, and $\mathrm{CO}$ and $\mathrm{CH}_{4}$ decomposition $[11,12]$. Thus, the development of SRF catalyst is of paramount importance to decrease the formation of these byproducts, to avoid the occurrence of side reactions and, especially, to increase the production of hydrogen.

Precious metals and transition metals such as nickel and cobalt supported on oxides have been thoroughly studied in the steam reforming reaction [12-21]. The present work is based on the use of cobalt supported on natural sepiolite as alternative to the more widespread use of precious metals. Co has an optimal performance at moderate temperatures and the substitution of precious metals by Co supposes a great advantage from the economic point of view. The optimal performance of Co is related to the facility that this metal has to carry out the scission of the C-C and O-H bonds [22-40]. In general, the adequate catalytic performance of one catalyst is determined by three main parameters: activity, selectivity, and stability. A multitude of factors around the catalyst affects significantly these three parameters such as the selected active metal phase, the precursor used for the incorporation of the metal phase in the support, the chosen support, the catalyst synthesis method, the operating conditions and the incorporation of additives. Among them, support is one of the most important factors to consider. Nature of the support is crucial to synthesize highly active, selective and stable steam reforming catalysts, because it can favor high dispersions of the active metal phase of the catalysts and favor metal-support interactions that improve the catalytic performance [39-41]. The method to incorporate the active phase (metals) is another important issue to synthesize efficient catalysts. Specifically, the method of incorporation of the metal phase into the support can influence dramatically the catalytic behavior of the synthesized catalyst [14]. Depending on the method chosen, high dispersions of the metal phase and support metal interactions can be favored [14]. In addition, acidic support seem to promote the formation of coke precursors (ethylene), which can affect the stability of the catalyst during the steam reforming reaction [39-48]. In this work, we show by the first time the use of Co-based catalysts supported on natural sepiolite in the production of hydrogen via furfural steam reforming. Two routes have been explored to incorporate cobalt in the sepiolitic support (PP and IWI) and their influence over the physicochemical characteristic of the synthesized catalysts has been studied in the steam reforming of furfural. The catalytic results show that the method of incorporation of Co has a significant impact on the activity, selectivity and stability of the furfural steam reforming catalyst. Characterization by XRD, TPR, surface area (BET) and TEM has helped to know that this impact is related 
to the particular characteristics presented by the metallic particles of cobalt supported such as their size, dispersion and reducibility.

\section{Experimental.}

\subsection{Catalyst preparation.}

The incorporation of Co over natural sepiolite (Tolsa Group, Pangel S9) was performed by incipient wetness impregnation (IWI) and precipitation (PP) methods. For IWI an aqueous solution containing the required amount of $\mathrm{Co}\left(\mathrm{NO}_{3}\right)_{2} \cdot 6 \mathrm{H}_{2} \mathrm{O}(98 \%$, Sigma-Aldrich) was used to achieve a concentration of Co of 15 wt.\%. After Co incorporation, the catalyst was dried over night at $100{ }^{\circ} \mathrm{C}$ and calcined in muffle oven at $600{ }^{\circ} \mathrm{C}$ for $3 \mathrm{~h}(\mathrm{Co} / \mathrm{Sep})$. In the precipitation method (PP), Co was introduced following the methodology described in literature [49] with some modifications. Specifically, two solutions were prepared. The first one contains $\mathrm{Co}\left(\mathrm{NO}_{3}\right)_{2} \cdot 6 \mathrm{H}_{2} \mathrm{O}\left(98 \%\right.$, Sigma-Aldrich) as cobalt precursor and $\mathrm{HNO}_{3}$ to achieve a final pH of 2 . The second solution contains the natural sepiolite $(0.11 \mathrm{~g}$ natural sepiolite/L). The first solution was added to the second one under agitation (rate of $1 \mathrm{~mL} / \mathrm{min}$ via a perfusion pump). $\mathrm{NaOH}$ was added to the final mixture to achieve a $\mathrm{pH}$ of 11 . After the mixture was filtered, dried at $100{ }^{\circ} \mathrm{C}$ for 3 hours and calcined at $600{ }^{\circ} \mathrm{C}$ for $3 \mathrm{~h}(\mathrm{CoSep})$.

\subsection{Catalyst characterization.}

Cobalt content in the catalytic material was determined by inductively coupled plasma with optical emission spectrometer (ICP-OES) in a Varian 700-ES Series.

Textural properties of the catalysts were obtained from the nitrogen adsorption isotherms, which were measured using an ASAP 2420 apparatus (Micromeritics) at $77 \mathrm{~K}$. Before the analysis, $200 \mathrm{mg}$ of each pellitized sample $(0.25-0.40 \mathrm{~mm})$ were degassed at $673 \mathrm{~K}$ with high vacuum $(\sim 5 \times 10-6$ bar $)$ overnight. The BET surface area was calculated by using the Brunauer-Emmett-Teller equation, pore volume was calculated by the t-plot method.

Nature of the crystalline phases present in the catalysts was determined by X-ray diffraction. XRD patterns were obtained at room temperature in a Philips X'pert diffractometer using monochromatized CuK $\alpha$ radiation. 
The size of the Co crystalline particle was determined from XRD data using the Scherrer equation [50] and by transmission electron microscopy (TEM). TEM imaging was conducted using a Philips CM-10 at 100 $\mathrm{kV}$ with samples deposited onto holey carbon grids using an ethanol dispersion.

TPR profiles were obtained by passing 5 vol. $\% \mathrm{H}_{2} / \mathrm{Ar}$ through $20 \mathrm{mg}$ of sample heated at $5{ }^{\circ} \mathrm{C} \mathrm{min}{ }^{-1}$ from ambient temperature to $900^{\circ} \mathrm{C}$ in a Micromeitrics Autochem 2910 equipment. About $50 \mathrm{mg}$ of the calcined catalyst was initially flushed with $30 \mathrm{~mL}$ min-1 of Ar at room temperature during $30 \mathrm{~min}$. Then a mixture of $10 \mathrm{vol} . \%$ of $\mathrm{H}_{2}$ in $\mathrm{Ar}$ was passed through the catalyst at a total flow rate of $50 \mathrm{~cm}^{3} \mathrm{~min}^{-1}$ while temperature was increasing up till $900^{\circ} \mathrm{C}$ at a heating rate of $10^{\circ} \mathrm{C} \mathrm{min}^{-1}$. The $\mathrm{H}_{2}$ consumption rate was monitored in a thermal conductivity detector (TCD) previously calibrated. The reduction degree was determined by TPR experiments comparing the total amount of hydrogen consumed by each catalyst with the theoretical amount of hydrogen that would be necessary to complete the reduction of $\mathrm{Co}_{2} \mathrm{O}_{3}$ in the catalyst.

Equation $\mathrm{D}=96 / \mathrm{d}(\mathrm{nm})[52,53]$ was used to calculate the dispersion of the metallic cobalt particles (D: percentage of dispersion, $\mathrm{d}$ : average particle size of the particles of metallic cobalt determined by TEM, in nanometers.

Carlo Erba 1106 analyzer was used to determine the amount of carbon deposited on the used catalysts.

\subsection{Catalyst activity evaluation.}

Reactions were carried out in a stainless tube, atmospheric pressure reactor between $400{ }^{\circ} \mathrm{C}$ and $600{ }^{\circ} \mathrm{C}$, $\mathrm{H} 2 \mathrm{O} / \mathrm{FUR}=7-84(\mathrm{~mol} / \mathrm{mol}), \mathrm{S} / \mathrm{C}=1-17$ and GHSV of $2300 \mathrm{~h}-1$. The range of S/C chosen to carry out the studies is justified considering the amount of water present in the non-useful aqueous phase obtained during the fast pyrolysis process $[10,15,54-57]$. The reactor was charged with $0.5 \mathrm{~g}$ of catalyst and $\mathrm{SiC}$ as diluent. The catalyst was pretreated with $100 \mathrm{~mL} \cdot \mathrm{min}^{-1} \mathrm{H}_{2}$ for $2 \mathrm{~h}$ at $600{ }^{\circ} \mathrm{C}$. Products were analyzed on stream via a Varian 3800 GC-FIC-TCD with a TRB-5 and CarboSieve SII columns.

Conversion of furfural and products selectivity were calculated on a molar basis using the totals of the observed products, excluding water. Definition here used for selectivity can be found sometime in literature as products selectivity or, more rigorously, as products distribution. The equations to determine conversion and selectivity to the different products are as follow:

$$
X_{F U R}(\%, m o l)=\frac{\left(F_{F U R}\right)_{0}-\left(F_{F U R}\right)_{f}}{\left(F_{F U R}\right)_{0}} \times 100
$$




$$
S_{j}(\%, m o l)=\frac{F_{j}}{\left(\sum F_{j}\right)_{\text {products }}} \times 100
$$

Where:

$\mathrm{X}_{\mathrm{FUR}}$ : conversion of furfural.

$\left(\mathrm{F}_{\mathrm{FUR}}\right)_{0}$ : furfural fed $\left(\mathrm{mol} \cdot \mathrm{s}^{-1}\right)$.

$\left(\mathrm{F}_{\mathrm{FUR}}\right)_{\mathrm{f}}$ : non-reacted furfural $\left(\mathrm{mol} \cdot \mathrm{s}^{-1}\right)$.

$S_{\mathrm{j}}$ : Selectivity to product $\mathrm{j}$.

$\mathrm{F}_{\mathrm{j}}: \operatorname{product} \mathrm{j}\left(\mathrm{mol} \cdot \mathrm{s}^{-1}\right)$.

\section{Results and discussion.}

\subsection{Characterization.}

Sepiolite structure and crystalline phases of Co present in the catalysts after calcination and reduction steps have been studied by XRD, Figure 1. As it can be seen, crystalline structure of natural sepiolite (JCPDS $13-595)$ is damaged after the incorporation of Co and the subsequent calcination at $600{ }^{\circ} \mathrm{C}$. In the calcined cobalt-based catalysts (CoSep cal and Co/Sep cal) several diffraction peaks corresponding to $\mathrm{CoO}$ (JCPDS 78-0431), $\mathrm{Co}_{3} \mathrm{O}_{4}$ (JCPDS 89-4037), $\mathrm{Co}_{2} \mathrm{SiO}_{4}$ (JCPDS 00-029-0506) and $\mathrm{Co}_{2} \mathrm{MgO}_{4}$ (JCPDS 98-003-0580) are observed. $\mathrm{CoO}$ and $\mathrm{Co}_{3} \mathrm{O}_{4}$ correspond to the oxidation of the cobalt precursor during the calcination step. Mixed oxides $\left(\mathrm{Co}_{2} \mathrm{SiO}_{4}\right.$ and $\left.\mathrm{Co}_{2} \mathrm{MgO}_{4}\right)$ are also formed during calcination by the interaction of cobalt precursor with the components of the sepiolitic support $\left(\mathrm{MgO}\right.$ and $\left.\mathrm{Si}_{2} \mathrm{O}\right)$. 


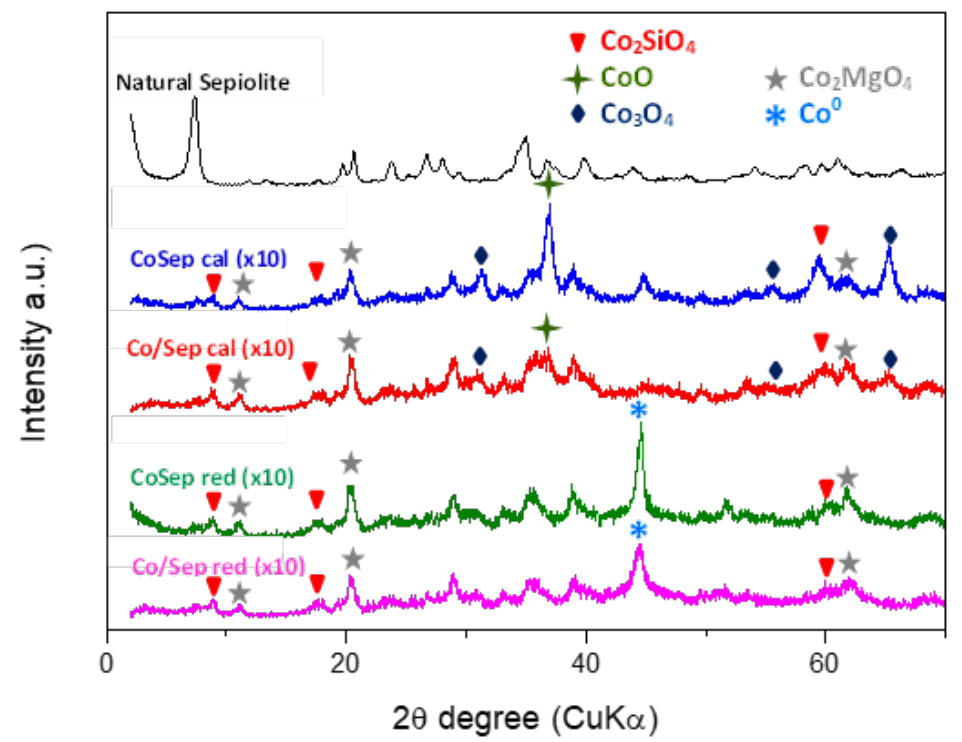

Figure 1. XRD of sepiolite as it was supplied (Natural Sepiolite) and calcined (CoSep cal and Co/Sep cal) and reduced (CoSep red and Co/Sep red) cobalt-based catalysts.

$\mathrm{XRD}$ of the reduced catalysts are also presented in Figure 1. As it can be seen, after reduction at $600{ }^{\circ} \mathrm{C}$, the peaks related to the cobalt oxides $\left(\mathrm{CoO}\right.$ and $\left.\mathrm{Co}_{3} \mathrm{O}_{4}\right)$ nearly disappear and a peak at 44 degrees, corresponding to metallic Co (JCPDS 00-015-0806), appears as consequence of the reduction process. On the other hand, $\mathrm{Co}_{2} \mathrm{SiO}_{4}$ and $\mathrm{Co}_{2} \mathrm{MgO}_{4}$ compounds remain in the catalyst after reduction step, suggesting that higher reduction temperatures would be necessary to reduce the Co presents in these compounds. The size of the metallic Co particles has been also determined from the XRD of the reduced catalyst using the Scherrer equation [50]. Table 1 shows that PP method makes possible to obtain metallic cobalt particles of smaller size than those obtained when the incipient wetness impregnation method is used (8 vs $12 \mathrm{~nm}$, respectively).

Co content and BET surface area of the cobalt-based catalysts (CoSep, Co/Sep) and natural septiolite are also shown in Table 1. The results of the ICP-OES technique show that the level of cobalt in both catalysts is very similar and close to $15 \mathrm{wt} . \%$. In relation to the textural properties, a decreasing of the BET surface area is detected for the sepiolitic support after the cobalt incorporation and calcination. This fact can be explained considering the loss of the sepiolite structure after the calcination at $600{ }^{\circ} \mathrm{C}$. In addition, the oxides of cobalt formed during calcination could be blocking the micropores of the support contributing also in the observed decreasing of the BET surface area [36]. In fact, when pore volume is determined for the sepiolite before and after the cobalt incorporation, a decrease is detected, supporting the pore blockage hypothesis. On the other hand, similar BET surface areas are presented by the cobalt-based catalysts, 
suggesting that the PP and IWI methods do not have a significant impact on the final BET surface area of the sepiolitic catalysts.

Table 1. Content of cobalt, surface area (BET), metallic cobalt particles size determined by XRD and TEM, metallic Co dispersion and reducibility at $600{ }^{\circ} \mathrm{C}$ for the catalysts studied in this work.

\begin{tabular}{|c|c|c|c|c|c|c|c|}
\hline Sample & $\begin{array}{c}\text { Co, } \\
\text { (wt.\%) }\end{array}$ & $\begin{array}{c}\text { BET } \\
\text { area } \\
\left(\mathrm{m}^{2} / \mathrm{g}\right)\end{array}$ & $\begin{array}{l}\text { Pore } \\
\text { Vol. } \\
\left(\mathrm{m}^{3} / \mathrm{g}\right)\end{array}$ & $\begin{array}{l}\mathrm{Co}^{0}, \\
\mathrm{XRD} \\
(\mathrm{nm})\end{array}$ & $\begin{array}{l}\mathrm{Co}^{0}, \\
\text { TEM } \\
(\mathbf{n m})\end{array}$ & $\begin{array}{c}\mathrm{Co}^{0} \\
\text { dispersion, } \\
(\%)^{\mathrm{a}}\end{array}$ & $\begin{array}{l}\text { Reducibility } \\
\%,\left(600{ }^{\circ} \mathrm{C}\right)\end{array}$ \\
\hline Sepiolite & - & 157 & 0.75 & - & - & - & - \\
\hline CoSep & 15.0 & 112 & 0.63 & 7 & 6 & 16.0 & 48.5 \\
\hline Co/Sep & 14.7 & 115 & 0.61 & 12 & 11 & 8.7 & 76.6 \\
\hline
\end{tabular}

(a) Calculated from $\mathrm{dCo}(\mathrm{nm})=96 / \mathrm{D}(\%)$, D: dispersion, $\mathrm{dCo}(\mathrm{nm})$ : metallic Co particle size (TEM).

The size of the metallic particles of cobalt was also determined by TEM to verify the size calculated before by XRD. Sizes are shown in Table 1. As it can be seen, similar sizes have been determined by TEM analysis ( $6 \mathrm{~nm}$ vs $7 \mathrm{~nm}$ for CoSep sample and 11 vs $12 \mathrm{~nm}$ for Co/Sep sample). However, the distribution of sizes is narrower for the catalyst prepared by PP, indicating that this sample presents a larger homogeneity of the sizes of the metallic particles of cobalt. Therefore, PP method would allow to prepare a sepiolitic catalyst with smaller metallic cobalt particles and with a more homogenous distribution. In addition, it should be noted that the cobalt incorporation by the PP method increases the dispersion of the metallic particles of Co on the sepiolitic support compared to the incipient wetness impregnation method (Table 1). The smaller size present in the catalyst CoSep, prepared by PP, could be associated to a higher metal-support interaction. This fact could be explained considering that it is possible that the PP method favors the housing and stabilization of the metallic cobalt particles in specials positions of the sepiolitic support where their sinterization would be prevented during the steps of calcination and reduction. On the contrary, the incipient wetness impregnation method does not seems to avoid successfully the sinterization of the metallic Co particles during the calcination and reduction steps as it can be deduced from the larger size of the metallic particles of cobalt present in this sample $(\mathrm{Co} / \mathrm{Sep})$. 


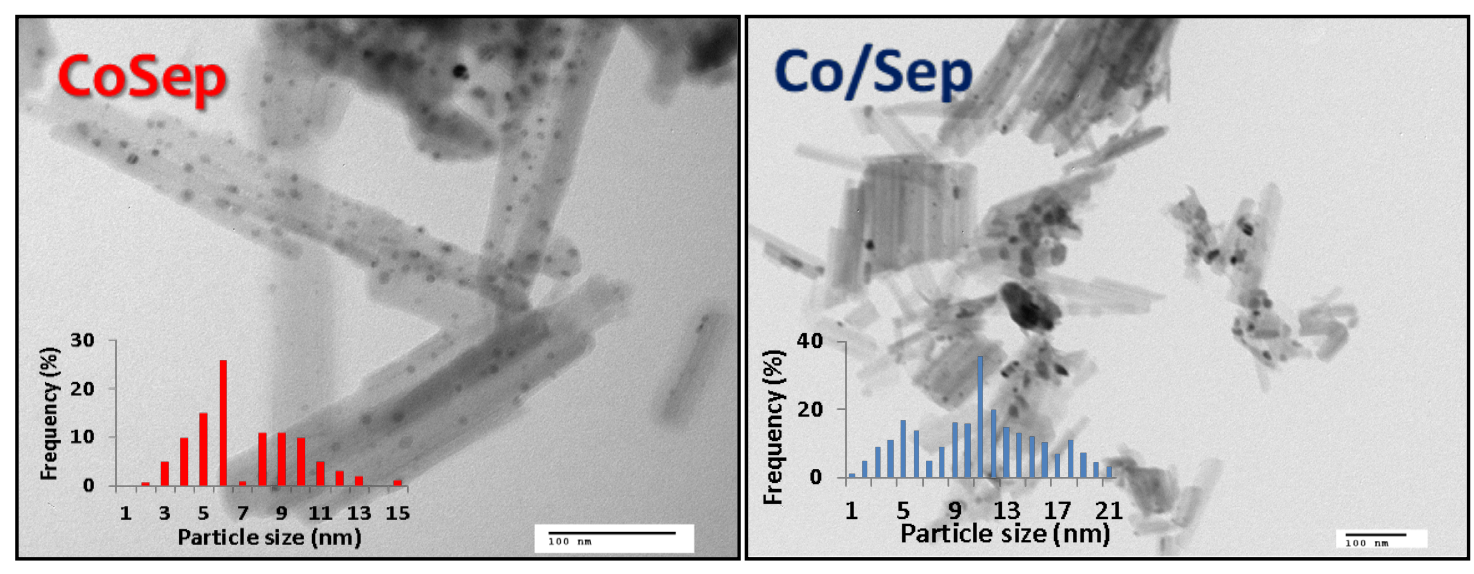

Figure 2. TEM images of reduced catalysts.

The reducibility of the catalysts has been also studied by temperature programmed reduction (TPR). TPR profile for each catalyst is shown in Figure 3. As it can be observed the reduction profile of the catalyst prepared by incipient wetness impregnation $(\mathrm{Co} / \mathrm{Sep})$ is very different compared to the catalyst prepared by precipitation (CoSep). As it can be seen, Co/Sep sample, prepared by IWI, presents four reduction peaks around $298,398,693$ and $763{ }^{\circ} \mathrm{C}$. The first two peaks correspond to the reduction of cobalt oxide $\left(\mathrm{Co}_{3} \mathrm{O}_{4}\right)$, the third is probably associated to the reduction of $\mathrm{Co}_{2} \mathrm{MgO}_{4}$ [57], and the last one corresponds to the reduction of $\mathrm{Co}_{2} \mathrm{SiO}_{4}$ [58], both formed during calcination step. Different reduction profile is exhibited by the sample prepared by precipitation (CoSep). This sample presents three main reduction peaks. In addition, the intensity of the reduction peaks exhibited by this sample was completely different. As it can be seen, CoSep sample presents a wide reduction peak at $325^{\circ} \mathrm{C}$, which would correspond to the first two peaks observed in the sample $\mathrm{Co} / \mathrm{Sep}$ (reduction of $\mathrm{Co}_{3} \mathrm{O}_{4}$ ). Two reduction peaks with high intensity are found at high reduction temperatures $\left(670\right.$ and $\left.766^{\circ} \mathrm{C}\right)$, which could be related to a larger concentration of $\mathrm{Co}_{2} \mathrm{MgO}_{4}$ and $\mathrm{Co}_{2} \mathrm{SiO}_{4}$ compounds where the Co results very difficult to reduce $[57,58]$. The degree of reduction of the oxidized Co phases present in the catalysts at $600{ }^{\circ} \mathrm{C}$ has been determined from the TPR profiles (Table 1). In the case of the catalyst obtained by precipitation (CoSep) was found a lower degree of reduction compared to the catalyst prepared by incipient wetness impregnation $\mathrm{Co} / \mathrm{Sep}$ ( $49 \%$ and $77 \%$, respectively). The differences found between both catalytic materials in the profiles and degree of reduction seems to be related to the size of the cobalt metallic particles (Table 1) and particularly with the presence of $\mathrm{Co}_{2} \mathrm{MgO}_{4}$ and $\mathrm{Co}_{2} \mathrm{SiO}_{4}$ where the Co results quite difficult to reduce. 


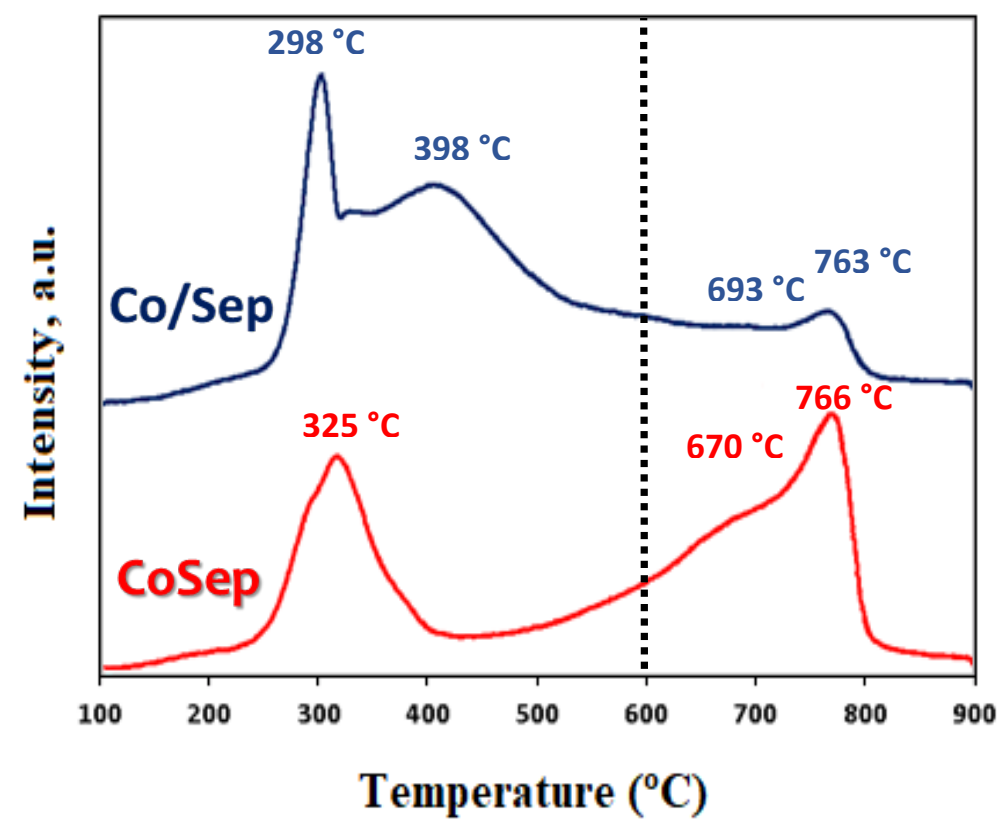

Figure 3. TPR of calcined catalysts. Dotted line corresponds to the temperature used for the reduction of the catalyst before reaction.

In summary, the Co incorporation method to synthesize catalysts based on sepiolite as support seems to have an important impact on the size, dispersion and reducibility of the metallic Co particles present. The precipitation method allows achieving smaller metallic cobalt particles and highly dispersing by favoring stronger interactions between cobalt and sepiolitic support.

\subsection{Catalytic activity.}

Catalytic activity and carbon balance was determined for each experiment. Carbon balance was found between 93 and $101 \%$ for all the experiments. Furfural conversion and hydrogen selectivity at $400{ }^{\circ} \mathrm{C}$ versus contact time is shown in Figures $4 \mathrm{a}$ and $4 \mathrm{~b}$, respectively. As it can be seen the incorporation of Co by PP method (CoSep) allows to obtain a catalytic material with higher activity than IWI method (Co/Sep). Specifically, furfural conversion values are between $20-95 \%$ for the sample prepared by PP (CoSep) and between $2-78 \%$ for the sample prepared by IWI $(\mathrm{Co} / \mathrm{Sep})$. The greater catalytic activity exhibited by the CoSep catalyst could be explained considering the smaller size of the metallic Co particles present in this sample and their higher dispersion, Table 1. Those results would mean that a larger number of active cobalt sites, where the steam reforming of furfural could occur, would be presented in this sample. This 
circumstance supports the importance of the synthesis method to prepare catalytic materials with improved catalytic performance. On the other hand, hydrogen selectivity was found quite similar for both catalysts $(60-70 \%)$. It seems that the Co incorporation method does not have a significant impact in the production of hydrogen. Other reaction products such as $\mathrm{CH}_{4}, \mathrm{CO}, \mathrm{CO}_{2}$ and $\mathrm{C}_{3} \mathrm{H}_{6} \mathrm{O}$ were also studied (Figures $4 \mathrm{c}$, $4 \mathrm{~d}$, 4e, and 4f). As it can be seen, the sample prepared by precipitation (CoSep) shows a lower production of $\mathrm{CO}$ (Figure 4c). For $\mathrm{CO}_{2}$ production, Figure 4d shows similar values for both catalysts, with small differences at high contact times. For methane production, Figure $4 \mathrm{e}$ shows that it is very low in both catalysts. Nevertheless, lower selectivity is presented by the catalyst prepared by PP. This is an interesting point since the formation of methane consumes hydrogen, diminishing its final production during the steam reforming of furfural. Finally, the acetone selectivity (Figure 4f) was lower for CoSep. The production of acetone is related to secondary reactions like furfural dehydration. Its presence suggests that the steam reforming reaction is not carrying out properly. Carbon balance was determined in all the experiment finding values between 94 and $102 \%$.
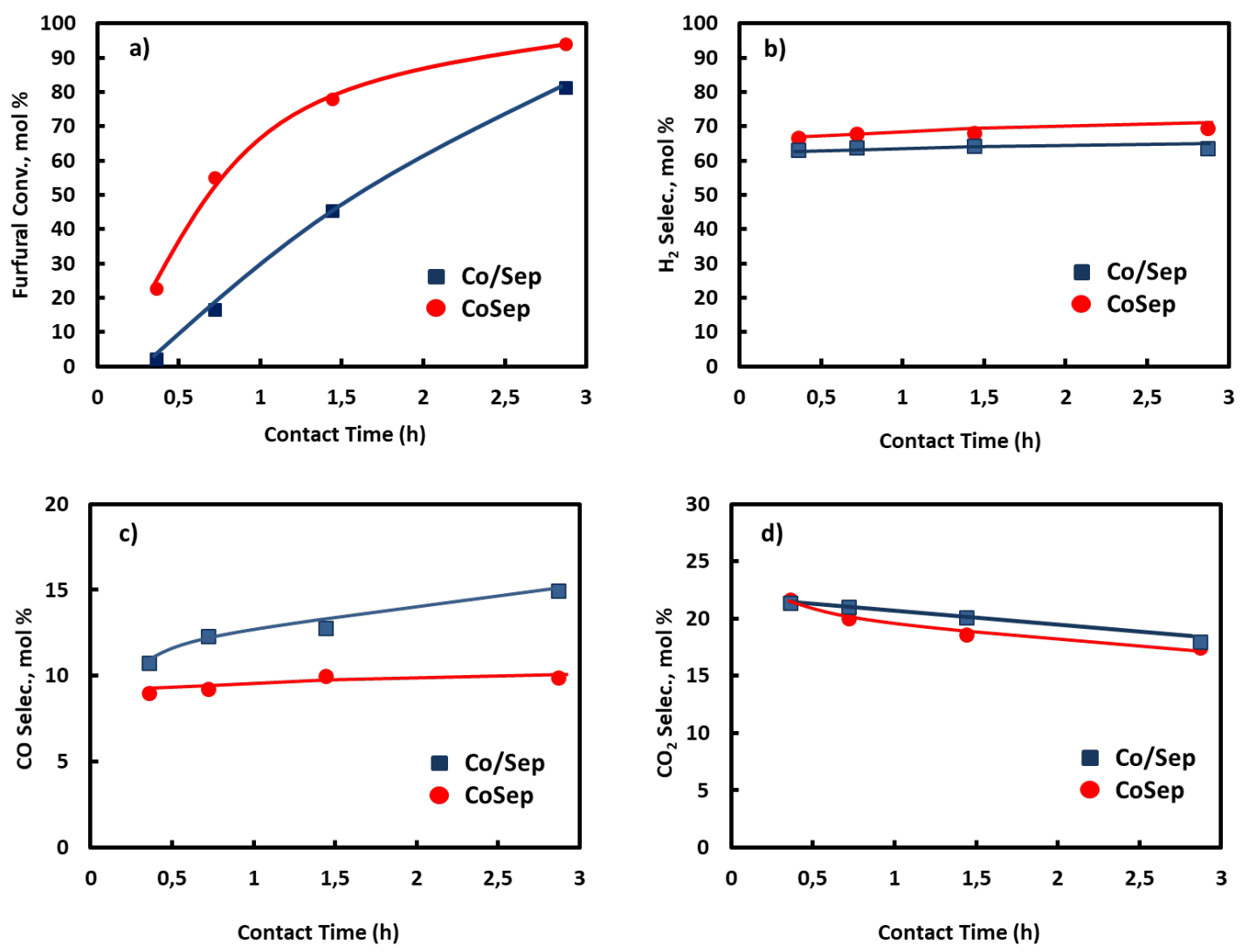

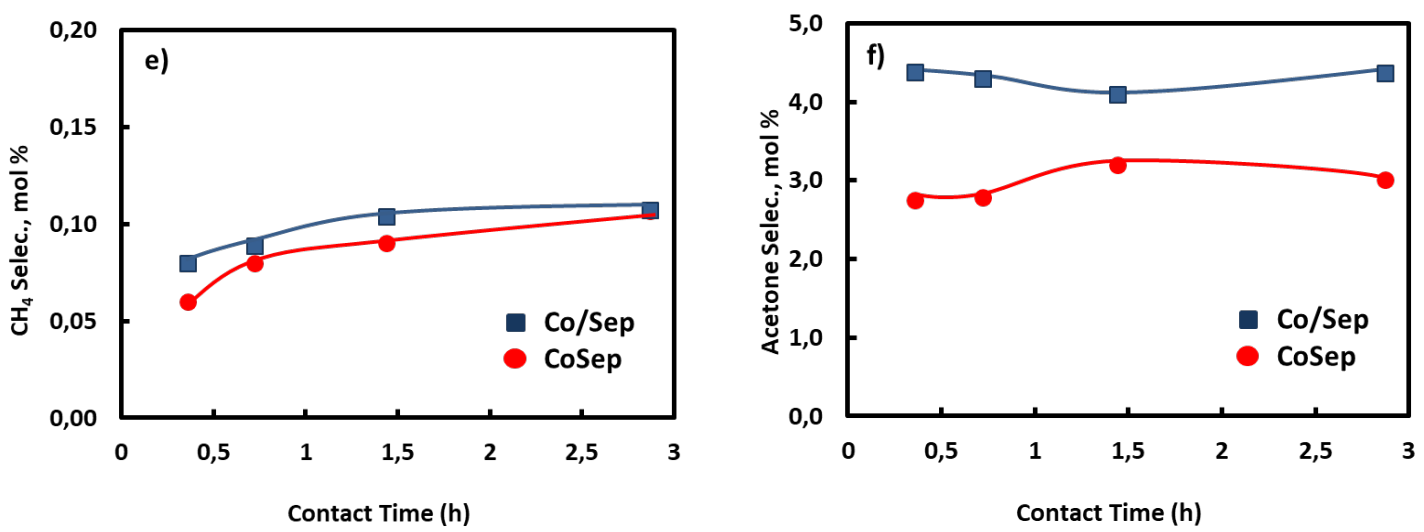

Figure 4. a) Conversion of furfural versus contact time. b) Hydrogen selectivity versus contact time. c) Selectivity to CO versus contact time. d) Selectivity to $\mathrm{CO}_{2}$ versus contact time. e) Selectivity to $\mathrm{CH}_{4}$ versus contact time. f) Selectivity to acetone versus contact time. (Reaction conditions: $\mathrm{T}^{\mathrm{a}}: 400^{\circ} \mathrm{C}$ and atmospheric pressure).

According to these results, the PP method could be considered a promising method for the incorporation of cobalt to synthesize sepiolitic catalysts highly active and selective in the steam reforming of furfural to produce hydrogen with low concentration of undesired by-products $\left(\mathrm{CO}, \mathrm{CO}_{2}, \mathrm{CH}_{4}\right.$ and acetone). The best results of CoSep could be explained considering its physiochemical properties such as the smaller metallic cobalt particles and highly dispersing by favoring stronger interactions between cobalt and sepiolitic support. In literature similar results on steam reforming of different biomass derived substrates (ethanol, glycerol, acetic acid as model for biooil) over Ni and Co catalysts are described, being the smaller size of their metallic particles and their higher dispersion the main responsible of the improved catalytic performance $[46,60-65]$.

\subsection{Catalytic deactivation.}

Catalytic stability is an important issue to consider for the properly performance of one catalyst. Stability is related to the deactivation of the catalyst with reaction time, which can be related with the formation of carbon deposits and sinterization of metallic active sites [65-70]. Catalytic activity of the catalyst prepared by PP (CoSep) and by IWI (Co/Sep) after 6 and $24 \mathrm{~h}$ of reaction time in shown in Table 2. Reaction conditions were adjusted to achieve similar furfural conversion levels. As it can be seen, deactivation happens in a larger extension for the catalyst prepared by incipient wetness impregnation, what could be explained considering the larger amount of coke presents in this sample (Table 2). 
Table 2. Conversion of furfural, carbon content, size and percentage of sinterization of metallic Co particles. Conversion data obtained after 6 and 24 hours of reaction time. Reaction conditions: (1) $\mathrm{H}_{2} \mathrm{O} / \mathrm{Fur}=18$ (mol/mol), contact time: $0.72 \mathrm{~h}, 400{ }^{\circ} \mathrm{C}$ and atmospheric pressure, (2) $\mathrm{H}_{2} \mathrm{O} / \mathrm{Fur}=18(\mathrm{~mol} / \mathrm{mol})$, contact time: $1.60 \mathrm{~h}, 400{ }^{\circ} \mathrm{C}$ and atmospheric pressure.

\begin{tabular}{|c|c|c|c|c|c|}
\hline Catalyst & $\begin{array}{c}\text { \%Conv. } \\
6 h\end{array}$ & $\begin{array}{c}\text { \%Conv. } \\
24 h\end{array}$ & $\begin{array}{l}\text { Carbon } \\
\text { (wt.\%) }\end{array}$ & $\begin{array}{c}\mathrm{Co}^{0}, \text { TEM } \\
(\mathrm{nm})\end{array}$ & $\begin{array}{c}\text { Sinterization, } \\
(\%)\end{array}$ \\
\hline $\operatorname{CoSep}^{(1)}$ & 54.9 & 52.4 & 17.0 & 10 & 36 \\
\hline $\mathrm{Co} / \operatorname{Sep}^{(2)}$ & 52.5 & 44.3 & 21.2 & 28 & 60 \\
\hline
\end{tabular}

Sinterization of metallic Co particles supported on the used catalyst has been also studied by TEM. The micrographs present in Figure 5 show clearly the formation of carbon nanotubes. In addition, it can be observed an increasing in the size of the metallic particles of Co after reaction. The level of metal sintering for the used catalysts has been calculated and presented in Table 2 . As it can be seen, it is significantly higher for the catalyst Co/Sep prepared by IWI (60\% versus 36\%, respectively). The furfural conversion fell a $17.5 \%$ in the catalyst prepared by the IWI method, while a $4.5 \%$ was the fall of the catalyst prepared by precipitation. Therefore, carbon deposition and sinterization of metallic cobalt particles could be considered the major responsible of the loss of activity detected for the sample prepared by incipient wetness impregnation.
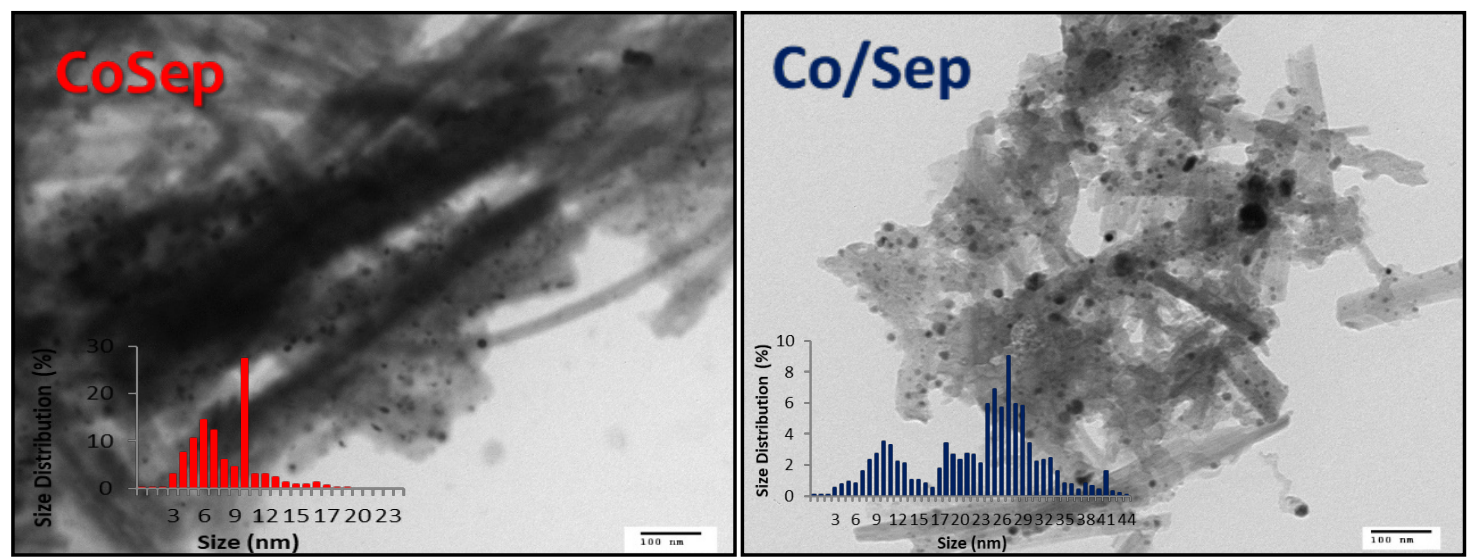

Figure 5. TEM images of catalysts after reaction. 
Catalytic results indicate that it has been possible to synthesize a cobalt-base catalyst supported on sepiolite with high catalytic performance in the steam reforming of furfural. In addition, it has been shown that the Co incorporation method has an important impact in the physicochemical properties of the final synthesized catalysts. Particularly, the particle size of the metallic cobalt, its interaction with the support and its reducibility are the most affected parameters. Specifically, it has been showed that the PP method makes possible to prepare a catalytic material based on sepiolite promoted with Co highly active and selectivity in the steam reforming of furfural, with high hydrogen yields, low production of unwanted by-products $(\mathrm{CO}$, $\mathrm{CH}_{4}$ and acetone) and with high stability (lower deposition of coke and specially, lower sintering of the metallic particles of $\mathrm{Co})$.

\section{Conclusions.}

Co incorporation on natural sepiolite have carried out by precipitation (PP) and incipient wetness impregnation (IWI) methods. The catalysts obtained have been characterized and studied in the steam reforming of furfural to produce hydrogen. High catalytic activity and hydrogen selectivity is exhibited by the catalyst prepared by precipitation (PP). In addition, selectivity to by-products $\left(\mathrm{CO}, \mathrm{CO}_{2}, \mathrm{CH}_{4}\right.$, acetone) is also minimized using this catalytic material (CoSep). Characterization data suggests that PP method makes possible to synthesize a cobalt catalyst supported on sepiolite with metallic particles of smaller size and well-dispersed on the sepiolite support. The smaller size and the higher dispersion, together with the high interaction cobalt-sepiolitic support, seem to explain the enhanced catalytic performance presented by the catalyst prepared by PP. In addition, the catalyst prepared by precipitation (CoSep) presented a larger catalytic stability with reaction time. Particularly, this sample exhibited slightly lower carbon deposition and, specially, lower degree of sinterization of the metallic particles of cobalt.

\section{Acknowledgements}

Thank you to the Spanish Government (Project RTI2018-102161-I00) and Generalitat Valenciana (PROMETEO/2018/006 grant) for the fanatical supporting. The support of the microscopy service at Universitat Politècnica de València (UPV) for the SEM and TEM analysis is also recognized.

\section{References}


[1] Ramírez-Salgado J, Estrada-Martínez Am. Roadmap towards a sustainable hydrogen economy in Mexico. Journal of Power Sources. 2004;129:255-63.

[2] Marquevich M, Sonnemann GW, Castells F, Montané D. Life cycle inventory analysis of hydrogen production by the steam-reforming process: comparison between vegetable oils and fossil fuels as feedstock. Green Chemistry. 2002;4:414-23.

[3] Dou B, Zhang H, Cui G, Wang Z, Jiang B, Wang K, et al. Hydrogen production by sorptionenhanced chemical looping steam reforming of ethanol in an alternating fixed-bed reactor: Sorbent to catalyst ratio dependencies. Energy Conversion and Management. 2018;155:24352.

[4] Dashtban M. Production of Furfural: Overview and challenges. J-FOR-Journal of science \& technology for forest products and processes. 2012;2:44-53.

[5] Sagehashi M, Nomura T, Shishido H, Sakoda A. Separation of phenols and furfural by pervaporation and reverse osmosis membranes from biomass - superheated steam pyrolysisderived aqueous solution. Bioresource Technology. 2007;98:2018-26.

[6] Vázquez M, Oliva M, Téllez-Luis SJ, Ramírez JA. Hydrolysis of sorghum straw using phosphoric acid: Evaluation of furfural production. Bioresource Technology. 2007;98:3053-60. [7] Peng J, Chen P, Lou H, Zheng X. Catalytic upgrading of bio-oil by HZSM-5 in sub- and supercritical ethanol. Bioresource Technology. 2009;100:3415-8.

[8] Spragg J, Mahmud T, Dupont V. Hydrogen production from bio-oil: A thermodynamic analysis of sorption-enhanced chemical looping steam reforming. International Journal of Hydrogen Energy. 2018;43:22032-45.

[9] Italiano C, Bizkarra K, Barrio VL, Cambra JF, Pino L, Vita A. Renewable hydrogen production via steam reforming of simulated bio-oil over Ni-based catalysts. International Journal of Hydrogen Energy. 2019;44:14671-82.

[10] Zhang F, Wang S, Chen J, Wang Y, Ru B, Zhu L. Effect of Coal Ash on the Steam Reforming of Simulated Bio-oil for Hydrogen Production over Ni/Y-Al2O3. BioResources; Vol 11, No 3 (2016). 2016.

[11] Bizkarra K, Barrio VL, Arias PL, Cambra JF. Sustainable hydrogen production from bio-oil model compounds (meta-xylene) and mixtures (1-butanol, meta-xylene and furfural).

Bioresource Technology. 2016;216:287-93.

[12] Trane-Restrup R, Jensen AD. Steam reforming of cyclic model compounds of bio-oil over Ni-based catalysts: Product distribution and carbon formation. Applied Catalysis B:

Environmental. 2015;165:117-27.

[13] Vispute TP, Huber GW. Production of hydrogen, alkanes and polyols by aqueous phase processing of wood-derived pyrolysis oils. Green Chemistry. 2009;11:1433-45.

[14] Sayas S, Chica A. Furfural steam reforming over Ni-based catalysts. Influence of Ni incorporation method. International Journal of Hydrogen Energy. 2014;39:5234-41.

[15] Whang HS, Choi MS, Lim J, Kim C, Heo I, Chang T-S, et al. Enhanced activity and durability of Ru catalyst dispersed on zirconia for dry reforming of methane. Catalysis Today. 2017;293294:122-8.

[16] Tahay P, Khani Y, Jabari M, Bahadoran F, Safari N. Highly porous monolith/TiO2 supported $\mathrm{Cu}, \mathrm{Cu}-\mathrm{Ni}, \mathrm{Ru}$, and $\mathrm{Pt}$ catalysts in methanol steam reforming process for $\mathrm{H} 2$ generation. Applied Catalysis A: General. 2018;554:44-53.

[17] Im Y, Lee JH, Kwak BS, Do JY, Kang M. Effective hydrogen production from propane steam reforming using M/NiO/YSZ catalysts ( $\mathrm{M}=\mathrm{Ru}, \mathrm{Rh}, \mathrm{Pd}$, and Ag). Catalysis Today. 2018;303:168-76. [18] Al-Fatesh A, Singh SK, Kanade GS, Atia H, Fakeeha AH, Ibrahim AA, et al. Rh promoted and ZrO2/Al2O3 supported $\mathrm{Ni} / \mathrm{Co}$ based catalysts: High activity for $\mathrm{CO} 2$ reforming, steam-CO2 reforming and oxy-CO2 reforming of $\mathrm{CH} 4$. International Journal of Hydrogen Energy. 2018;43:12069-80.

[19] Shoynkhorova TB, Simonov PA, Potemkin DI, Snytnikov PV, Belyaev VD, Ishchenko AV, et al. Highly dispersed Rh-, Pt-, Ru/Ce0.75Zr0.25O2- $\delta$ catalysts prepared by sorption-hydrolytic 
deposition for diesel fuel reforming to syngas. Applied Catalysis B: Environmental. 2018;237:237-44.

[20] Katheria S, Deo G, Kunzru D. Rh-Ni/MgAl2O4 catalyst for steam reforming of methane: Effect of Rh doping, calcination temperature and its application on metal monoliths. Applied Catalysis A: General. 2019;570:308-18.

[21] Yadav AK, Vaidya PD. A study on the efficacy of noble metal catalysts for butanol steam reforming. International Journal of Hydrogen Energy. 2019;44:25575-88.

[22] Llorca J, Homs N, Sales J, de la Piscina PRr. Efficient Production of Hydrogen over Supported Cobalt Catalysts from Ethanol Steam Reforming. Journal of Catalysis. 2002;209:30617.

[23] Lin SSY, Kim DH, Ha SY. Hydrogen Production from Ethanol Steam Reforming Over Supported Cobalt Catalysts. Catalysis Letters. 2008;122:295-301.

[24] Lin SSY, Kim DH, Ha SY. Metallic phases of cobalt-based catalysts in ethanol steam reforming: The effect of cerium oxide. Applied Catalysis A: General. 2009;355:69-77. [25] Lin SSY, Kim DH, Engelhard MH, Ha SY. Water-induced formation of cobalt oxides over supported cobalt/ceria-zirconia catalysts under ethanol-steam conditions. Journal of Catalysis. 2010;273:229-35.

[26] Batista MS, Santos RKS, Assaf EM, Assaf JM, Ticianelli EA. Characterization of the activity and stability of supported cobalt catalysts for the steam reforming of ethanol. Journal of Power Sources. 2003;124:99-103.

[27] Haga F, Nakajima T, Miya H, Mishima S. Catalytic properties of supported cobalt catalysts for steam reforming of ethanol. Catalysis Letters. 1997;48:223-7.

[28] Song H, Zhang L, Ozkan US. Effect of synthesis parameters on the catalytic activity of CoZrO2 for bio-ethanol steam reforming. Green Chemistry. 2007;9:686-94.

[29] Llorca J, de la Piscina PRr, Dalmon J-A, Sales J, Homs Ns. CO-free hydrogen from steamreforming of bioethanol over ZnO-supported cobalt catalysts: Effect of the metallic precursor. Applied Catalysis B: Environmental. 2003;43:355-69.

[30] Llorca J, Homs Ns, Sales J, Fierro J-LG, Ramírez de la Piscina P. Effect of sodium addition on the performance of $\mathrm{Co}-\mathrm{ZnO}$-based catalysts for hydrogen production from bioethanol. Journal of Catalysis. 2004;222:470-80.

[31] Batista MS, Santos RKS, Assaf EM, Assaf JM, Ticianelli EA. High efficiency steam reforming of ethanol by cobalt-based catalysts. Journal of Power Sources. 2004;134:27-32.

[32] Song H, Zhang L, Watson RB, Braden D, Ozkan US. Investigation of bio-ethanol steam reforming over cobalt-based catalysts. Catalysis Today. 2007;129:346-54.

[33] Wang H, Ye JL, Liu Y, Li YD, Qin YN. Steam reforming of ethanol over Co3O4/CeO2 catalysts prepared by different methods. Catalysis Today. 2007;129:305-12.

[34] Llorca J, Homs N, Ramirez de la Piscina P. In situ DRIFT-mass spectrometry study of the ethanol steam-reforming reaction over carbonyl-derived $\mathrm{Co} / \mathrm{ZnO}$ catalysts. Journal of Catalysis. 2004;227:556-60.

[35] Llorca J, Dalmon J-A, Ramírez de la Piscina P, Homs Ns. In situ magnetic characterisation of supported cobalt catalysts under steam-reforming of ethanol. Applied Catalysis A: General. 2003;243:261-9.

[36] Cerdá-Moreno C, Da Costa-Serra JF, Chica A. Co and La supported on Zn-Hydrotalcitederived material as efficient catalyst for ethanol steam reforming. International Journal of Hydrogen Energy. 2019;44:12685-92.

[37] Da Costa-Serra JF, Guil-López R, Chica A. Co/ZnO and Ni/ZnO catalysts for hydrogen production by bioethanol steam reforming. Influence of $\mathrm{ZnO}$ support morphology on the catalytic properties of $\mathrm{Co}$ and $\mathrm{Ni}$ active phases. International Journal of Hydrogen Energy. 2010;35:6709-16.

[38] Da Costa-Serra JF, Chica A. Catalysts based on Co-Birnessite and Co-Todorokite for the efficient production of hydrogen by ethanol steam reforming. International Journal of Hydrogen Energy. 2018;43:16859-65. 
[39] Hernández-Soto MC, Da Costa-Serra JF, Carratalá J, Beneito R, Chica A. Valorization of alcoholic wastes from the vinery industry to produce $\mathrm{H} 2$. International Journal of Hydrogen Energy. 2019;44:9763-70.

[40] Da Costa-Serra JF, Chica A. Bioethanol steam reforming on Co/ITQ-18 catalyst: Effect of the crystalline structure of the delaminated zeolite ITQ-18. International Journal of Hydrogen Energy. 2011;36:3862-9.

[41] Chica A, Sayas S. Effective and stable bioethanol steam reforming catalyst based on $\mathrm{Ni}$ and Co supported on all-silica delaminated ITQ-2 zeolite. Catalysis Today. 2009;146:37-43.

[42] Montero C, Remiro A, Valle B, Oar-Arteta L, Bilbao J, Gayubo AG. Origin and Nature of Coke in Ethanol Steam Reforming and Its Role in Deactivation of Ni/La2O3- $\alpha \mathrm{Al} 2 \mathrm{O} 3$ Catalyst. Industrial \& Engineering Chemistry Research. 2019;58:14736-51.

[43] Wu R-C, Tang C-W, Huang H-H, Wang C-C, Chang M-B, Wang C-B. Effect of boron doping and preparation method of $\mathrm{Ni} / \mathrm{Ce} 0.5 \mathrm{Zr0} 0.5 \mathrm{O} 2$ catalysts on the performance for steam reforming of ethanol. International Journal of Hydrogen Energy. 2019;44:14279-89.

[44] Elias KFM, Bednarczuk L, Assaf EM, Ramírez de la Piscina P, Homs N. Study of Ni/CeO2$\mathrm{ZnO}$ catalysts in the production of $\mathrm{H} 2$ from acetone steam reforming. International Journal of Hydrogen Energy. 2019;44:12628-35.

[45] Di Michele A, Dell'Angelo A, Tripodi A, Bahadori E, Sànchez F, Motta D, et al. Steam reforming of ethanol over $\mathrm{Ni} / \mathrm{MgAl} 2 \mathrm{O} 4$ catalysts. International Journal of Hydrogen Energy. 2019;44:952-64.

[46] Fang W, Romani Y, Wei Y, Jiménez-Ruiz M, Jobic H, Paul S, et al. Steam reforming and oxidative steam reforming for hydrogen production from bioethanol over Mg2AINiXHZOY nanooxyhydride catalysts. International Journal of Hydrogen Energy. 2018;43:17643-55.

[47] gharahshiran VS, Yousefpour M. Synthesis and characterization of Zr-promoted Ni-Co bimetallic catalyst supported OMC and investigation of its catalytic performance in steam reforming of ethanol. International Journal of Hydrogen Energy. 2018;43:7020-37. [48] Palma V, Ruocco C, Meloni E, Ricca A. Highly active and stable Pt-Ni/CeO2-SiO2 catalysts for ethanol reforming. Journal of Cleaner Production. 2017;166:263-72.

[49] Romé JS, Orozco FJL, Díez EA, Berenguer AÁ, Corral JM, García CP. Method of preparing metallic nanoparticles and materials thus obtained. WO/2005/035124; 2005.

[50] Cullity BD. Elements of X-ray Diffraction. In: Company AWP, editor.1956. p. 261-2.

[51] Romar H, Rivoire E, Tynjälä P, Lassi U. Effect of Calcination Conditions on the Dispersion of Cobalt Over Re, Ru and Rh Promoted Co/Y-Al2O3 Catalysts. Topics in Catalysis. 2017;60:140814.

[52] Borg $\varnothing$, Eri S, Blekkan EA, Storsæter S, Wigum H, Rytter E, et al. Fischer-Tropsch synthesis over $\gamma$-alumina-supported cobalt catalysts: Effect of support variables. Journal of Catalysis. 2007;248:89-100.

[53] Cheng F, Dupont V, Twigg MV. Direct reduction of nickel catalyst with model biocompounds. Applied Catalysis B: Environmental. 2017;200:121-32.

[54] Remón J, Broust F, Volle G, García L, Arauzo J. Hydrogen production from pine and poplar bio-oils by catalytic steam reforming. Influence of the bio-oil composition on the process. International Journal of Hydrogen Energy. 2015;40:5593-608.

[55] Artetxe M, Alvarez J, Nahil MA, Olazar M, Williams PT. Steam reforming of different biomass tar model compounds over Ni/Al2O3 catalysts. Energy Conversion and Management. 2017;136:119-26.

[56] Zhang L, Yu Z, Li J, Zhang S, Hu S, Xiang J, et al. Steam reforming of typical small organics derived from bio-oil: Correlation of their reaction behaviors with molecular structures. Fuel. 2020;259:116214.

[57] Wang HY, Ruckenstein E. Formation of filamentous carbon during methane decomposition over Co-MgO catalysts. Carbon. 2002;40:1911-7. 
[58] Steen Ev, Sewell GS, Makhothe RA, Micklethwaite C, Manstein H, de Lange M, et al. TPR Study on the Preparation of Impregnated Co/SiO2Catalysts. Journal of Catalysis. 1996;162:2209.

[59] Finocchio E, Rossetti I, Ramis G. Redox properties of Co- and Cu-based catalysts for the steam reforming of ethanol. International Journal of Hydrogen Energy. 2013;38:3213-25.

[60] Ashok J, Dewangan N, Das S, Hongmanorom P, Wai MH, Tomishige K, et al. Recent progress in the development of catalysts for steam reforming of biomass tar model reaction. Fuel Processing Technology. 2020;199:106252.

[61] Rossetti I, Lasso J, Finocchio E, Ramis G, Nichele V, Signoretto M, et al. TiO2-supported catalysts for the steam reforming of ethanol. Applied Catalysis A: General. 2014;477:42-53. [62] Xu W, Liu Z, Johnston-Peck AC, Senanayake SD, Zhou G, Stacchiola D, et al. Steam Reforming of Ethanol on $\mathrm{Ni} / \mathrm{CeO} 2$ : Reaction Pathway and Interaction between $\mathrm{Ni}$ and the $\mathrm{CeO} 2$ Support. ACS Catalysis. 2013;3:975-84.

[63] Nichele V, Signoretto M, Menegazzo F, Rossetti I, Cruciani G. Hydrogen production by ethanol steam reforming: Effect of the synthesis parameters on the activity of Ni/TiO2 catalysts. International Journal of Hydrogen Energy. 2014;39:4252-8.

[64] de Lima SM, da Silva AM, da Costa LOO, Assaf JM, Jacobs G, Davis BH, et al. Evaluation of the performance of $\mathrm{Ni} / \mathrm{La2O}$ catalyst prepared from LaNiO3 perovskite-type oxides for the production of hydrogen through steam reforming and oxidative steam reforming of ethanol. Applied Catalysis A: General. 2010;377:181-90.

[65] Vizcaíno AJ, Carrero A, Calles JA. Hydrogen production by ethanol steam reforming over $\mathrm{Cu}-\mathrm{Ni}$ supported catalysts. International Journal of Hydrogen Energy. 2007;32:1450-61.

[66] Barroso MN, Gomez MF, Arrúa LA, Abello MC. Hydrogen production by ethanol reforming over NiZnAl catalysts. Applied Catalysis A: General. 2006;304:116-23.

[67] Wang Y-H, Liu H-M, Xu B-Q. Durable Ni/MgO catalysts for $\mathrm{CO} 2$ reforming of methane: Activity and metal-support interaction. Journal of Molecular Catalysis A: Chemical.

2009;299:44-52.

[68] Saraswat SK, Pant KK. Synthesis of hydrogen and carbon nanotubes over copper promoted $\mathrm{Ni} / \mathrm{SiO} 2$ catalyst by thermocatalytic decomposition of methane. Journal of Natural Gas Science and Engineering. 2013;13:52-9.

[69] Haryanto A, Fernando S, Murali N, Adhikari S. Current Status of Hydrogen Production Techniques by Steam Reforming of Ethanol: A Review. Energy \& Fuels. 2005;19:2098-106. [70] Fuertes A, Da Costa-Serra JF, Chica A. New Catalysts based on Ni-Birnessite and NiTodorokite for the Efficient Production of Hydrogen by Bioethanol Steam Reforming. Energy Procedia. 2012;29:181-91. 